\title{
RECURSOS PEDAGÓGICOS DE MUSEUS: “KITS” DE OBJETOS ARQUEOLÓGICOS E ETNOGRÁFICOS
}

\section{Introdução}

\begin{abstract}
A Divisão de Difusão Cultural do MAE, dentro de seu Programa de Recursos Pedagógicos e Museográficos, possui seis "kits" pedagógicos com objetos arqueológicos e etnográficos os quais foram projetados para serem utilizados em atividades educativas principalmente com público escolar. ${ }^{1}$

A prática pedagógica que sensibiliza os educandos em relação ao "universo dos objetos" é bastante importante para que eles tenham experiências concretas que possibilitem um bom entendimento sobre o mundo contemporâneo.

Os objetos que nos rodeiam propiciam uma relação direta entre nós e quem os fez, usou e guardou, desde que tenhamos a possibilidade de interpretá-los. Assim, podemos compreender
\end{abstract}

(1) Os "kits" foram criados pelas educadoras do antigo MAE: Célia Maria Cristina Demartini, Denise Cristina Catunda Marques e Judith Mader Elazari, sob a coordenação da Profa. Dra. Elaine Hirata , em 1990, como parte do Projeto Museu vai à escola à noite. Hoje ele se apresenta de uma forma bastante modernizada $\mathrm{e}$ prática, tendo sido elaborada pelo projetista gráfico Sergio Kon, graças ao financiamento conseguido junto à VITAE.

Esse Projeto foi aplicado inicialmente por apenas uma educadora, mas para que ele pudesse atingir um público escolar mais amplo, os professores passaram a ser capacitados para utilizarem este material didático, através de Treinamentos e Cursos. Esses tinham a duração de trinta horas, divididas em dez semanas. Eram discutidos vários conceitos e conteúdos relacionados aos objetos arqueológicos e etnográficos contidos no "kit"; os professores visitavam os "bastidores" do museu (laboratórios, biblioteca, laboratório museográfico etc.) e trabalhavam com os objetos do "kit" como sujeitos da aprendizagem.

Este "kit" também foi utilizado na atividade educativa Museu vai à escola, durante o período em que a exposição de longa duração "Formas de Humanidade" estava sendo montada. Os educadores iam às escolas e trabalhavam os conhecimentos possíveis de serem construídos através deste recurso pedagógico.

Desde 1998, o "kit" tem sido usado no Curso de Extensão Universitária Caminhos e possibilidades da Educação Infantil no MAE, ministrado na DDC-MAE. melhor a história do povo ao qual os objetos pertencem ou pertenceram.

Por serem concretos e visíveis, os objetos tanto envolvem como desenvolvem nossos sentidos quando os olhamos, tocamos, cheiramos, ouvimos e mesmo os degustamos. E, podendo manuseá-los, os sentimos mais plenamente.

Objetos nos motivam a investigar, analisar, discutir, pesquisar informações e também possuem muitas vezes uma simbologia especial sobre a qual precisamos nos inteirar. A partir de sua análise, eles podem, inclusive, estimular novas criações.

Podemos ir além dos currículos escolares através dos objetos, trabalhando com conceitos importantes, assim como com informações diversificadas. Este recurso pedagógico é também inestimável por ser menos sujeito a preconceitos que outros vestígios humanos, sendo assim menos propenso a atitudes estereotipadas frente a povos que o público escolar não conhece bem.

Precisamos "aprender a ler" os objetos e assim os teremos como um estimulante material didático. $^{2} \mathrm{E}$ de que maneira? Através de certos procedimentos (habilidades) intelectuais, tais como: observação, investigação, dedução, descrição, pesquisa, identificação, classificação, registro, avaliação, instigação etc., que nos possibilitam desenvolver o processo de aprendizagem do envolvido no que se refere a observação e apreciação.

Sistematizar as especificidades dos objetos que se quer conhecer é fundamental. Para tal, é aconselhável o uso de um Roteiro de Análise de

(2) Consideraremos como material didático o que "no acesso ao conhecimento tem a função de ser mediador na comunicação entre o professor e o aluno (...). Isto é, são materiais didáticos tanto os elaborados especificamente para o trabalho de sala de aula - livros, manuais, apostilas e vídeos - como também os não produzidos para esse fim, mas que são utilizados pelo professor para criar situações de ensino". (PARÂMETROS CURRICULARES NACIONAIS DE HISTÓRIA (1998). 
Objetos $^{3}$ que nos possibilite utilizar os procedimentos acima. Assim, fica mais claro, para quem estiver analisando os objetos, o que se quer saber sobre eles e porque estamos fazendo a sua análise. A aprendizagem pode se desenvolver através de qualquer tipo de objeto. O importante é que se aplique este Roteiro primeiramente com objetos mais próximos do grupo envolvido e posteriormente com os de um "kit" temático.

Este tipo de atividade educacional deve ser realizado levando-se sempre em conta os saberes que os educandos já possuem devido a suas vivências anteriores.

O manuseio e a análise direta dos objetos nem sempre nos fornecem todas as informações sobre eles. Há necessidade de pesquisas posteriores mais aprofundadas, em livros, documentos, vídeos, filmes, construções, museus etc. e algumas vezes são levantadas hipóteses que não são esclarecidas totalmente.

\section{Os "kits" pedagógicos de objetos arqueológicos e etnográficos do MAE}

O MAE possui "kits" com objetos arqueológicos e etnográficos, que são emprestados aos docentes interessados. ${ }^{4}$ Eles possibilitam ao professor, em conjunto com os seus alunos, utilizar recursos pedagógicos direcionados aos conhecimentos específicos sobre diferentes

(3) Este Roteiro permite questionarmos o objeto quanto a: características físicas, construção, função/utilização, design, valor e sociedade que o produziu.

(4) O "kit" contém cinco categorias de componentes: a) Objetos arqueológicos e etnográficos (autênticos e réplicas): instrumentos líticos (ponta de projétil lascada; raspador lascado; furador lascado; lâmina de machado polida; bloco lascado e percutor para lascamento); objetos cerâmicos (fragmento de vasilha; lamparina greco-romana; utensílio Karajá) e pente Waiwai. b) Painéis sobre a produção de alguns de seus objetos (confecção de lamparinas e de objetos cerâmicos com a técnica de roletes; lascamento de rochas; painel com imagem de lamparina e textos contemporâneos à lamparina.

c) Textos contemporâneos à lamparina greco-romana. d) Subsídios teóricos para os professores trabalharem com o "kit" pedagógico.

e) Feltro para espalhar os objetos antes do seu manuseio. culturas estudadas por arqueólogos e etnólogos, que pesquisam principalmente os vestígios materiais das sociedades que os produzem (Fotos 1 e 2).

Esta prática pedagógica leva em conta também objetivos mais específicos, tais como:

- Oferecer a oportunidade a alunos, professores e outros públicos, de manusear, observar e analisar estes objetos;

- Discutir a relação possível entre diferentes documentos deixados ou usados pelo Homem: escritos, materiais e iconográficos, identificando as contribuições, alcances e limitações de cada um deles para o estudo e ensino principalmente de História;

- Mostrar a necessidade de os museus atuarem também como laboratório pedagógico, experimentando e propondo formas alternativas de ensino e aprendizagem;

- Preparar professores para que estes motivem o público escolar a visitar as exposições do MAE e também de outras instituições museológicas;

- Experimentar os atributos educacionais de diferentes recursos didáticos.

\section{Ação educativa desenvolvida através do "kit" pedagógico}

Os trabalhos educativos que podemos desenvolver com este recurso pedagógico são muitos. Sugerimos um Roteiro o qual muitas vezes aplicamos e orientamos professores a utilizá-lo. Ele se desenvolve em duas etapas:

\section{$1^{a}$ etapa}

Esta etapa, que dura cerca de duas horas, é o primeiro contato que os alunos têm com o conteúdo do "kit" e envolve:

a. Relaxamento (alunos sentados no chão, em círculo), tendo os objetos do "kit" no centro, cobertos por um feltro) .

b. Sondagem: troca de idéias entre os alunos e o educador sobre seus conhecimentos a respeito da instituição museu e sobre os museus que já visitaram.

c. Manuseio dos objetos: os alunos têm oportunidade de sentir os objetos e observarem as suas características principais (Foto 3).

d. "As peças falam...": os objetos são contextualizados através das questões que o professor passa a fazer, e os alunos, na medida em que as respondem, começam a construir várias informaçōes sobre as sociedades que os produziram/usaram, tais como: matéria-prima, técnica de produção, função/ 
utilização, quem usou ou quem fez etc.. Nesta fase são utilizados os painéis sobre a produção de alguns dos objetos do "kit" (Fotos 4 e 5).

e. Formulação de conceitos (eles serão construídos a partir da análise destes objetos e do que os levou a ser resgatados e preservados): Arqueologia, Etnologia, Museu, Cultura, Patrimônio Cultural e outros. Sempre se considera a faixa etária com a qual se está trabalhando para que esses conceitos sejam compreendidos da forma mais adequada possível.

\section{$2^{a}$ etapa}

Esta etapa, que tem a duração aproximada de duas horas, se torna mais produtiva se for desenvolvida em um segundo dia e consta das seguintes fases:

a. Recordação do que foi visto no contato anterior, procurando-se, principalmente, destacar o objeto como suporte de informações e os conceitos construídos a partir deles.

b. Análise do utensílio lamparina (documento material), ${ }^{5}$ da representação de sua imagem em vaso contemporâneo (documento iconográfico) (Foto 6) e de textos sobre a sua utilização (documento escrito). ${ }^{6}$ Através desses três tipos de documentos, é possível discutir a potencialidade informativa de cada um deles e a integração das informações para a melhor compreensão da sociedade que os produziu.

c. Avaliação da ação educativa desenvolvida através deste recurso pedagógico por meio de: questões, desenhos, dramatização, elaboração de textos, montagem de museu na escola, construção de "sítio arqueológico" para que seja escavado e analisado pelos alunos, e outras possibilidades.

\section{Treinamento de Professores para utilização dos "kits" pedagógicos}

Este material pedagógico esta disponível no MAE para ser emprestado aos professores interessados. Como, porém, o seu potencial

(5) Vide este objeto assinalado na Foto 2.

(6) Os textos são os seguintes:

Heródoto, VII, 215: “ (...) Eles deixaram o campo na hora em que se acendem as lamparinas".

Platão, Conv., 218c: Com efeito, senhores, quando a lamparina foi apagada (...)"

Aristófanes, $\mathrm{Nu}$. 56: "Não há mais óleo na lamparina".

Xenofonte, Conv.VII, 4: "Por exemplo, por que então a lamparina, por que ela tendo uma chama brilhante ilumina (...)". educativo é bastante amplo e muito complexo para ser aplicado por professores ou outras pessoas interessadas sem uma preparação prévia, é necessário que haja uma orientação especializada para o seu uso. São oferecidos Treinamentos para o público docente nos quais se desenvolvem várias atividades, tais como:

1. Discussão e análise de conceitos básicos: Cultura, Diversidade Cultural, Arqueologia, Etnologia, Patrimônio Cultural e outros, os quais são fundamentais para a contextualização dos objetos do "kit" pedagógico.

2. Análise de diferentes objetos, inclusive os dos "kits" do MAE: quando o professor se torna o receptor da ação educativa o que o qualifica mais adequadamente para o seu trabalho com os seus alunos (Foto 7 ).

3. O professor adquire apostilas com textos teóricos a partir dos quais poderá contextualizar mais profundamente os objetos arqueológicos e etnográficos do "kit".

O Treinamento tem a duração de quatro horas e, depois de participar de um deles, o professor poderá tomar emprestado, por quinze dias, $o$ "kit". Para tal, assina um Termo de Responsabilidade e leva um Questionário de Avaliação que deve ser respondido após a utilização do material pedagógico e devolvido juntamente com o "kit".

No final de cada semestre, todos os participantes dos Treinamentos são convidados a retornarem ao MAE para trocarem as experiências que tiveram com a utilização do "kit" e discutirem alguns dos pontos levantados nos Questionários de Avaliação. ${ }^{7}$ É nesta ocasião que constatamos a versatilidade deste material pedagógico. Os professores nem sempre seguem o Roteiro sugerido durante o Treinamento. Eles elaboram situações educativas de diferentes tipos , muito criativas.

\section{Considerações finais}

Este material pedagógico que evidencia a importância dos objetos como fonte de informações importantes e valiosas pode ser utilizado

(7) Dados de 1996 a 2000 demonstram que os "kits" foram emprestados para cerca de noventa escolas, num total aproximado de 8.500 alunos. Há professores que solicitam o "kit" durante anos seguidos e outros mais de uma vez no mesmo ano, donde se constata que adotaram em seu Planejamento de Curso este recurso pedagógico. 
também como subsídio para o professor preparar, em sala de aula, seus alunos para uma visita livre ou monitorada à exposição de longa duração "Formas de Humanidade" do MAE, capacitando-os para a apreciação e análise dos bens culturais lá expostos. Estarão trabalhando dentro dos princípios da Educação Patrimonial, cuja metodologia é seguida e aplicada na ação educativa da DDC/MAE. ${ }^{8}$

Considera-se que os recursos pedagógicos criados e divulgados por um museu, dentro de seus programas educativos, fazem parte da premissa que "cabe a esta instituição propiciar experiências inovadoras de aprendizagem de forma a alargar o espaço destinado ao livre questionamento por parte dos estudantes, suscitando o aparecimento de idéias novas"; assim como "criar condições adequadas e estimulantes para o exercício das potencialidades do indivíduo, usando de linguagem que lhe é própria, e que está expressa no seu acervo" (Hirata, Demartini, Peixoto, Elazari 1989: 15).

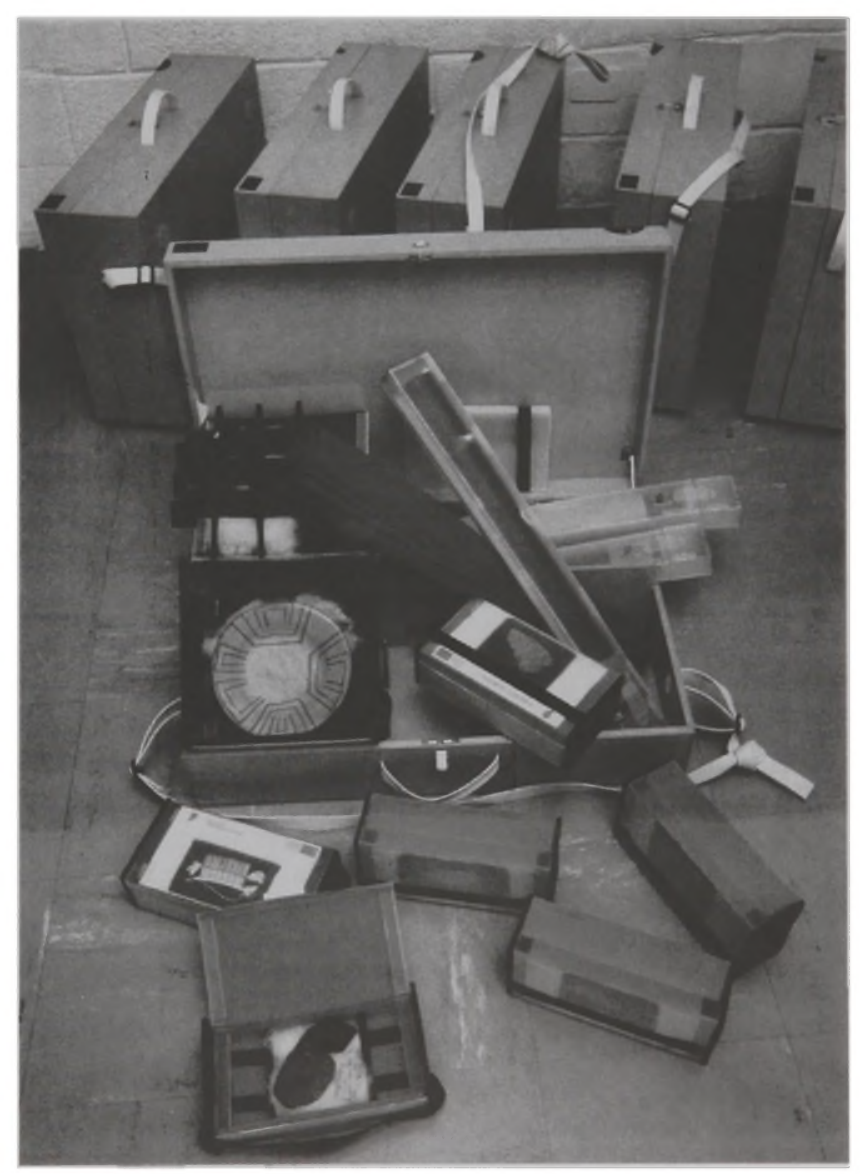

Foto 1 - Os "kits"pedagógicos interna e externamente.

(8) A Educação Patrimonial se refere ao "ensino centrado nos bens culturais, como a metodologia que toma estes bens como ponto de partida para desenvolver a tarefa pedagógica; que considera os bens culturais como fonte primária de ensino" (Grunberg (1995: 6). Para um maior conhecimento desta metodologia e seus princípios teóricos, pode-se consultar Horta et al. (1999). 
Notas - Revista do Museu de Arqueologia e Etnologia, São Paulo, 10: 351-358, 2000.

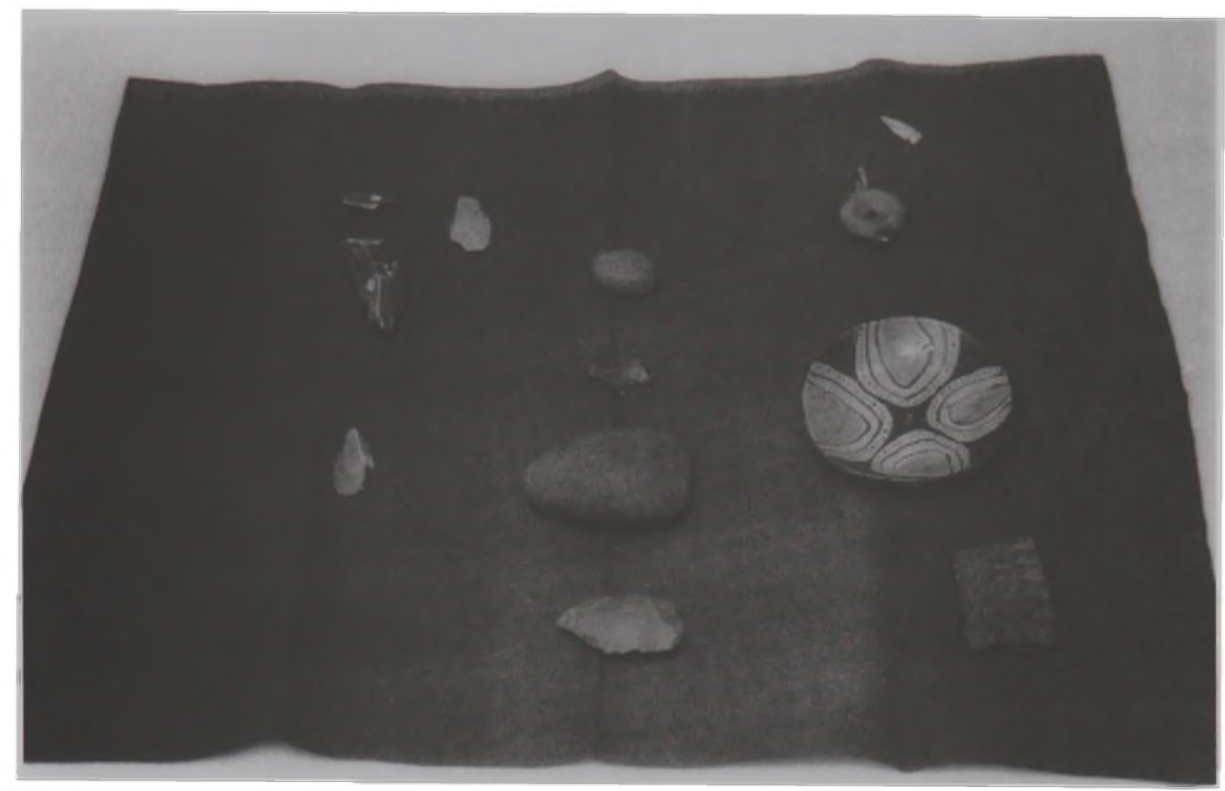

Foto 2 - Alguns objetos do "kit" pedagógico.

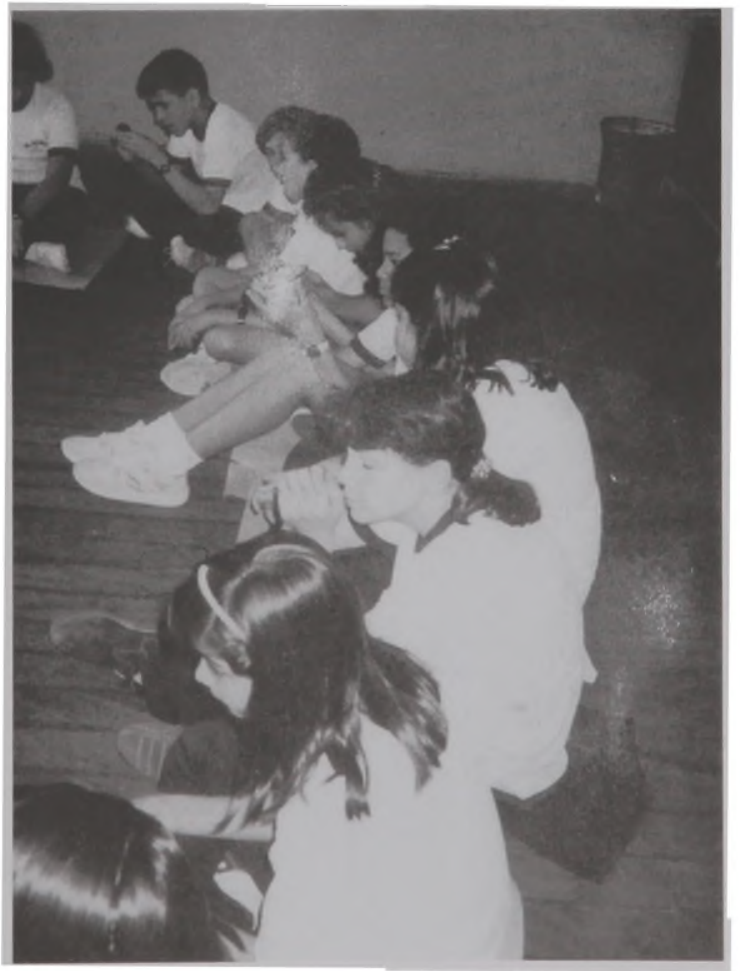

Foto 3 - Alunos manuseando objetos do "kit" pedagógico. 

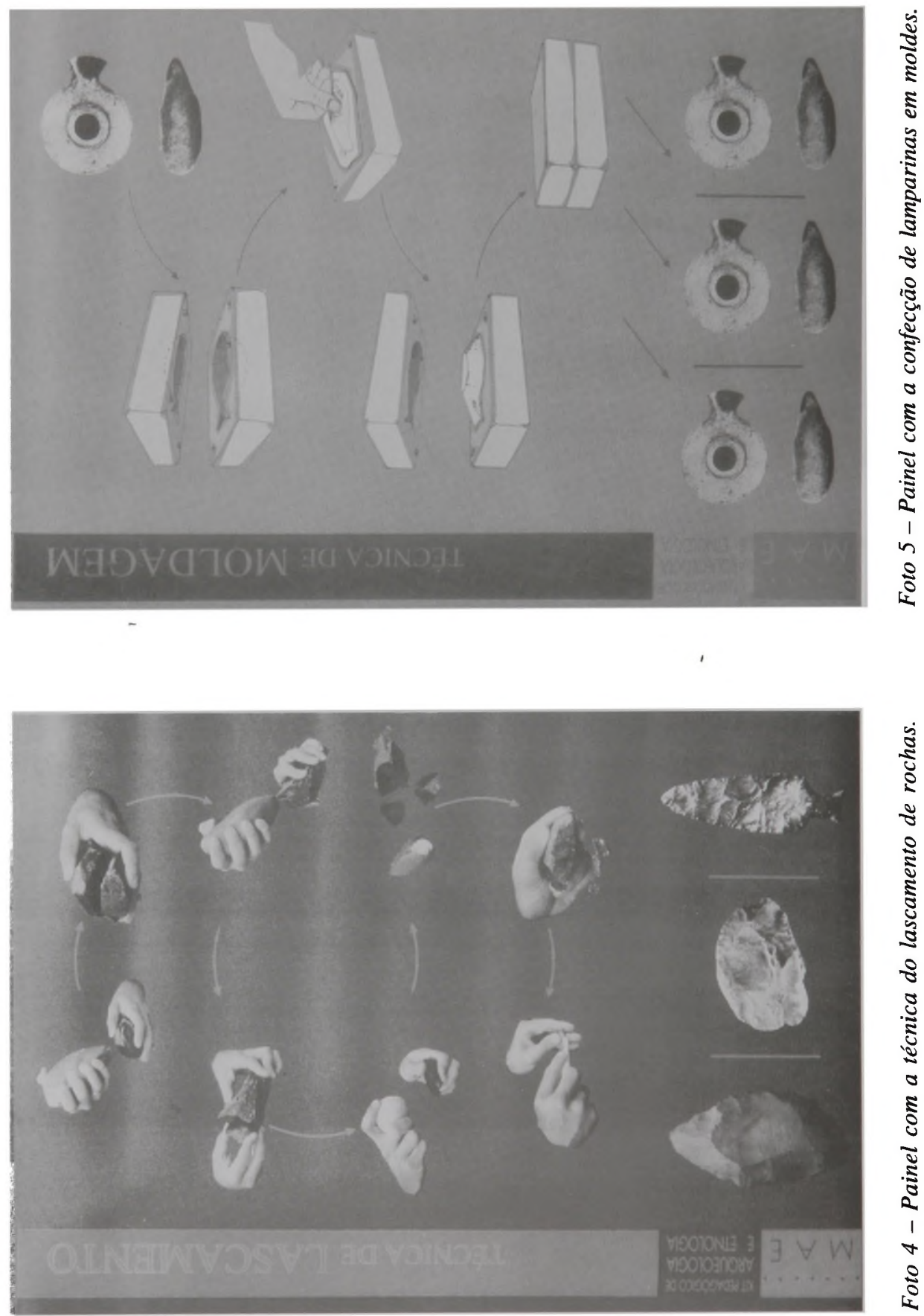

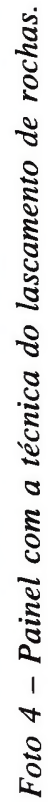


Notas - Revista do Museu de Arqueologia e Etnologia, São Paulo, 10: 351-358, 2000.

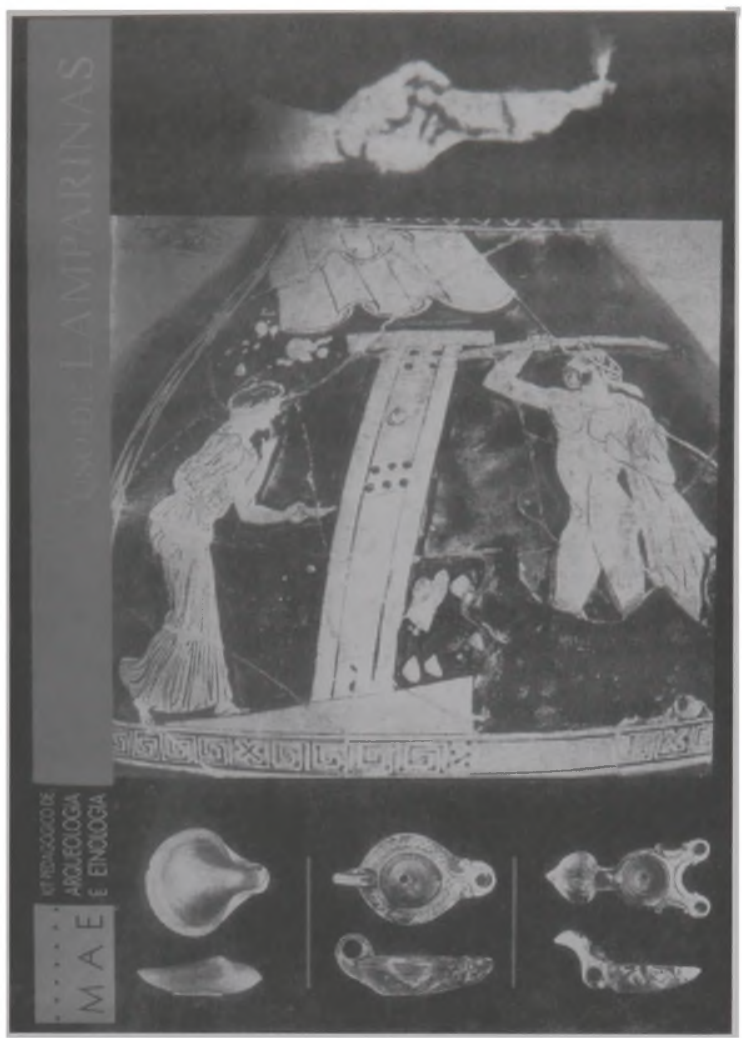

Foto 6 - Painel com foto de vaso contemporâneo ao uso de lamparinas, ilustrando sua utilização.

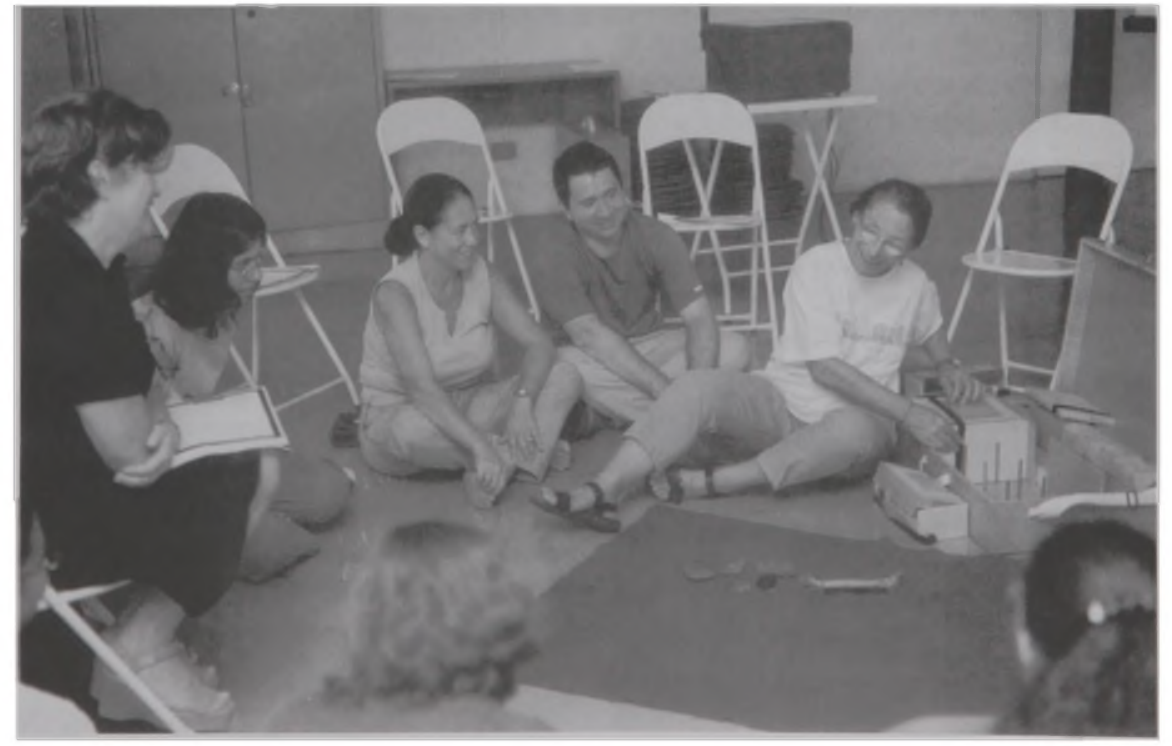

Foto 7 - Treinamento de professores para a utilização do "kit" pedagógico. 


\section{Bibliografia}

DURBIN, G.; MORRIS, S.; WILKINSON, S.

1990 A teacher's guide to learning from objects. London: English

Heritage.

FREIRE, P.

1998 Pedagogia da autonomia. São Paulo: Paz e Terra.

GRUNBERG, E.

1995 Educação Patrimonial - a utilização de bens culturais como recursos educacionais. S. Miguel, RS, Encontro de Museus do Mercosul, outubro (digitado).

HIRATA, E.F.V.; DEMARTINI, C.M.C.; PEIXOTO, D.C.C.; ELAZARI, J.M.

1989 Arqueologia, educação e museu: o objeto enquanto instrumentalização do conhecimento, Dédalo, São Paulo, 27: 11-45.
HORTA, M.L.P.; GRUNBERG, E.; MONTEIRO, A.Q. 1999 Guia Básico de Educação Patrimonial. Brasília, IPHAN, Museu Imperial.

\section{PARÂMETROS CURRICULARES NACIONAIS}

1998 Parâmetros Curriculares Nacionais de História (Ensino Fundamental).

1993 Roman Gallery Resource Pack: Notes for Teachers. London, The Museum of London. SECCO, M.F.F.V.

1991 Coleção didática de Zoologia para alunos de $1^{\circ} \mathrm{e} 2^{\circ}$ graus. Ciências em Museus., 3: 51-56.

Judith Mader Elazari*
(*) Museu de Arqueologia e Etnologia da Universidade de São Paulo. Divisão de Difusão Cultural, Serviço Técnico de Musealização, Área de Educação. 